\title{
Flipped Classroom Based on Micro Learning Resource in Experiment Teaching of Embedded System Design
}

\author{
Nan Ding, Yuxin Wang, Xiao Dong, Fan Wang \\ School of Computer Science and Technology \\ Dalian University of Technology, DUT \\ Dalian, China \\ dingnan@dlut.edu.cn
}

\begin{abstract}
The teaching methods of Micro Learning Resource (MLR) and flipped classroom are used in this paper, combining the information professional "embedded system design" course and characteristics of its experimental teaching links, reform on experimental links supporting the course is carried out pertinently. This paper elaborates on course characteristics and existing problems, MLR production, teaching method and course examination. Through the application and practice effect in practical teaching for multiple semesters, this reform shows that the flipped classroom mode based on MLR has significant effect in experimental links of embedded system design, which helps excite and mobilize the students' learning interest and enthusiasm at the same time of improving the teaching quality.
\end{abstract}

Keywords-Micro Learning Resource; Flipped Classroom; Embedded System Design.

\section{INTRODUCTION}

The embedded system is a product integrating advanced computer technology, semiconductor technology and electronic technology, and specific application of various industries. With the development needs of the Internet of things, Internet + and Industries 4.0, embedded system technology and its application are almost everywhere[1]. The rapid development of embedded system and the shortage of talents in the embedded system in the society at present bring opportunities to universities[2]. Therefore, embedded system has become an important course closely combining software and hardware in computer major of colleges, which is course with strong engineering practice following hardware courses such as electronic circuit, digital logic and principle of computer composition, playing an important role in the cultivation of computer talents of both "hard" and "soft". However, in computer colleges and universities at present, the embedded system experiment is a weak link with some problems, so it is necessary to carry out teaching reform on it.

MLR is a situational, interesting and visualized digital learning resource pack well designed and developed aiming at knowledge points or teaching links of a discipline with brief micro streaming media teaching video as the carrier, which supports various new learning methods such as flipped learning, blended learning, mobile learning and fragmented learning, etc.[3]. This method can further promote the implementation of flipped classroom; namely, achieve the purpose of knowledge communication through watching and learning MLR video outside class, which realizes the internalization of knowledge through discussion with teachers in class, and changes roles of teachers and students in traditional teaching, thus to realize the reform on the teaching mode.[4]

Thus, the aided teaching mode introduced with MLR applied in experimental teaching links of embedded system not only can let students understand relevant background of the teaching and excite their learning interest, but also visually show the practice process of the experiment, thus to achieve the purpose of preview, which helps students with experimental practice in limited class hours. In this paper, with the embedded course as the pilot, the study focuses on teaching method of experimental practice links of MLR aided specialized courses. This is an effective attempt to cultivation of the students' innovative practice ability in information specialized courses, which plays an exemplary role in the reform on teaching method of other specialized courses.

\section{TEACHING CHARACTERISTICS OF EMBEDDED SYSTEM COURSE AND EXPERIMENTAL LINKS, AND ANALYSIS OF CURRENT SITUATION}

\section{A. Course Content of embedded System and the Characteristics}

Most of experts and scholars believe that the embedded system is not an independent discipline, because the embedded system courses are related to not only courses in computer major, but also specific application background [5]. Correspondingly, the course system of embedded system should be set from "top" to "bottom", driving the history with the present, and advanced embedded course with in-depth content is set up according to the major characteristics, to facilitate the students to grasp the leading edge

This work was supported in part by the Graduate Education Reform Foundation of Dalian University of Technology No.JG2016019. 
content of the embedded system within a short period, and avoid multiple specialized courses with repeated content set up according to the development process. The role of basic courses and the difference with specialized courses should be concerned, to set up courses containing crossed integration of basic content such as information theory, system theory and control theory, thus to broaden the students' horizons, depth and breadth of thinking in the learning field. The course content can be divided into the following three aspects.

1) Course content of embedded system oriented basic teaching: Its cultivation objective is to enable the students to carry out the secondary development aiming at software and hardware platform of a specific embedded system, and grasp design and development ability of the application system. Its main content is to introduce development, application and characteristics of the embedded system aiming at the software and hardware platform of a specific embedded system. The embedded operating system should be generally introduced on the software platform, for example, one or more commonly used embedded operating systems such as $\mu \mathrm{C}$ OS-II, Android, And Linux, introduction of development tool and development language of embedded application system, establishment of cross-compilation environment, commissioning tool and network programming technology under embedded environment, and development methodology of embedded application software system. The introduction of hardware platform is concentrated on system structure of microprocessor and its assembly language, and working principle of peripheral interface, etc.. The key point is to grasp the use of development tool, development language, cross-compilation environment and commissioning tool of the embedded application system, and the interpretation to other content serves for grasping of the above content.

2) Course content of embedded system oriented development ability training: It includes some representative embedded CPUs, such as internal register structure of ARM series CPU, assembly instruction system, interruption management mechanism and common peripheral interface. The course of design and development of embedded system software platform is mainly to teach the common principle of embedded operating system and its transplant on the specific hardware platform, enabling the students to have the capabilities of embedded system cutting and transplant, initialization and drive capability of onboard resources, development of peripheral driver, and development technology of embedded database under specific hardware platform.

3) Course content of embedded system oriented innovative $R \& D$ : Its cultivation objective is to enable the students to carry out design and development of SoC system based on FPGA, and make theoretical study on computer system structure with combination of the development of the embedded system. This level mainly focuses on excellent undergraduates and postgraduates in colleges and universities, and scientific research institutes. Starting from the practice, the teaching content takes the system design as the core, adding teaching content such as co-design of hardware and software, design of hardware circuit, and software optimization, etc.

\section{B. Experimental Teaching of embedded System and the existing Problems}

The embedded system is a course with strong engineering practicality, and the corresponding experimental teaching links are matched always aiming at the content of theoretical teaching. At present, most domestic schools always allocate theoretical class hours and experimental class hours in the proportion of 1:1, and even some universities specially set up independent course of embedded experiment, to facilitate the students to better grasp the practical skills such as development of embedded software system and development of hardware system as well as comprehensive design and development. However, just because the embedded system is a specialized course integrating software and hardware, which needs support of multiple prophase courses. The experimental teaching links of embedded system face the following problems at present.

1) Experiment content is relatively simple: Because of extensive teaching objects, the students are always from different majors, such as major of computer application technology, major of automation, and electronics, etc.. Thus, the students have different foundations and abilities in prophase specialized courses. It causes there are too many validation experiments in the arrangement of the embedded experiment, and the students' designing experiments are few. There are many single experiments, few comprehensive development experiments, and the experimental content reflecting embedded advanced technology is little. The experimental content mainly focuses on foundations, which is seldom connected with the social needs and the embedded technology application. These factors do not help the students play their personalities and cultivate their innovation abilities.

2) More attentions on results and fewer attentions on the process: Since quantitative and verifiable means are mainly used in the traditional examination mechanism, the students are scored according to experimental reports or demonstration effect. At the same time, because experimental class hours are few, and exercise on experimental skills are overemphasized, the students mechanically make record processing of instrument use and adjustment, experiment steps and data, to obtain the results conforming to the theory, and thought, analysis and study on experimental phenomena and results are few. The students generally believe that few achievements are made in embedded system experiment, failing to feel how about application prospect and vitality of the embedded technology. Thus, the effect of experimental teaching is poor.

3) Lack of effective communication mechanism, and inadequate participation degree of the students: The experimental class hours of the embedded system in schools are generally 24 class hours and more. Because the students are ill-prepared before the experiment, they depend much on the teacher. Usually, the teacher in the experiment class needs to spend much time to tell the 
principle of embedded experiment and operating method of experimental platform. In terms of time, the students can operate in a systematic way according to the teacher's requirement, without free space. In addition, the students have not recognized the important of embedded system experiment to the cultivation of computer software and hardware comprehensive ability mentally, and they believe that the common basic experiment is seldom connected with the society, which is lack of assistance to personal development of future work. Thus, the students lack the enthusiasm in hands-on practice, and interest in the embedded system experiment, especially the confidence in the new technology and difficulty. At the same time, because of shortage of funds, the experimental equipment in urgent need of updating cannot be eliminated and replaced, and the existing embedded hardware platform functions cannot be kept up with the development of the embedded technology, which is relatively poor and backward. Although the students have new ideas, they can only give up when they need new technology of the embedded system to realize the innovative idea because the existing experimental platform cannot provide the new interface path.

\section{EMBEDDED SYSTEM ORIENTED MLR AND ITS CONSTRUCTION}

With video as the carrier, MLR integrates various learning sources, and explains a knowledge point pertinently in 3-10 minutes, without complex course system and various teaching objectives. The time of MLR is short, but it is a complete teaching process, including introduction, key points, difficulties and summary of the knowledge. The most important thing is that MLR can be repeatedly played, and the students can learn at any time. It meets the students' personalized learning of knowledge points of different disciplines, for the learner's preview, review after class, leak filling, strengthening and expanding, to greatly improve the learner's autonomy and enthusiasm.

MLR can be produced by mobile phone, digital camera, DV, and screen record software such as Camtasia Studio, Screen Recorder, and the operation is very simple. The teacher only needs to prepare other teaching sources of the course such as PPT, pictures, animations and videos before recording. The following points should be noticed for the production of micro video of information course: (1) Sound and picture are synchronous, and the operation of mouse and keyboard can be noted by graph; (2) The theoretical explanation parts presents the teacher's image, and strengthens the learner's true presence; (3) The knowledge of key points and difficulties should be highlighted or marked.

Combined with the content related to the embedded experiment teaching, relevant materials are produced according to MLR production steps such as selection of topic, analysis of teaching content, learner's analysis, clarification of teaching objective and teaching strategy. Each MLR lasts 3-10 minutes, which is brief in diversified forms, and updated at any time. The individual requirement of the student is met, to facilitate the student to learn at any time and in any place.

\section{IMPROVEMENT AND MEASURES FOR TEACHING LINKS OF EMBEDDED EXPERIMENT BASED ON MLR}

\section{A. Reform Thought}

In order to meet the student's individual requirement, and facilitate the students to learn at any time and in any place, the data of MLR can be published in real time by network communication mode such as QQ and WeChat. Depending on the rich network resources at present, the students can download the relevant data conveniently. Preview should be ensured in modes such as installation of experimental platform, building of experimental environment, and introduction to experimental background, etc.. The students can save part time through the preview, thus to provide more time for realization and commissioning of experiment code. Especially the students who have the ability to learn more can fully use the experimental resources for the free development, and carry out part exploratory experiment.

By the form integrating written examination, experimental report, participation and degree of practical innovation, the student's learning effect is evaluated comprehensively and objectively. The project team is responsible for the examination of the embedded course, which is carried out in the form integrating written examination and experimental report. The written examination focuses on the examination of student's grasping degree of basic concept and design method, and the experimental report focuses on the examination of the student's collaboration on the completion of the embedded experiment. Combined with the network assisted teaching platform, the student's participation in course selection period as well as practice and innovation of the experimental links can be further reflected. It mainly aims at certain achievements of students participating in practice and innovation in experimental links.

\section{B. Measures for mobilizing the students' Active learning of embedded Experiment with MLR}

Cultivating the student' $s$ interest is the primary task of experimental teaching of embedded system. The interest is the best teacher, and how to improve the student' $s$ interest and creative ability of the embedded technology by MLR is an important link in improvement and measures of teaching links of embedded experiment.

1) The interesting MLR video is used to arouse the curiosity, to stimulate learning interest and enthusiasm. For example, "Watching mobile phone development for 30 years in 3 minutes", the mobile phone is a representative product, which goes 
deep into life. Through the development of mobile phone, the increasing reform on the embedded technology is reflected vividly, to promote the students' concerns and stimulate their interest.

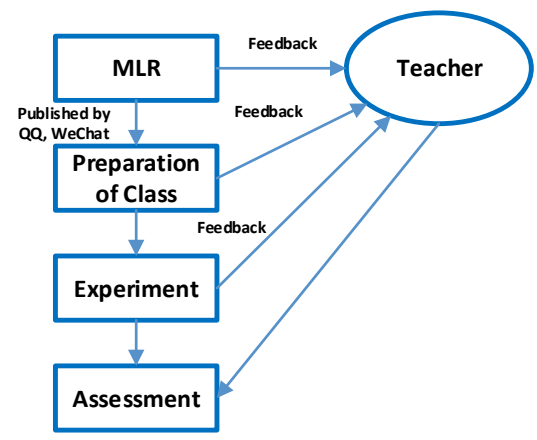

Fig. 1. Experimental teaching and examination based on MLR

2) Before teaching the experimental content, the teacher fully uses animation or video to briefly and intuitively explain the experiment program by MLR, to win time for hands-on practice of the students. At the same time, the students are promoted to preview the experimental content as well as related data and instructions, etc., and promote the students to form the good preview habit.

\section{Examination Methods and Measures}

In order to supervise the students to carefully complete the embedded experiment, and really check the student's experimental hands-on and experimental observation ability, the scores of the embedded experiment course can be divided into: (1)Theoretical achievements of written examination mainly focuses on the examination of the student's grasping of principle of embedded experiment, experimental objective, experimental method and precautions for the experiment; (2)Achievements of experimental process include attendance of the students in each experiment class, specific operation and experimental report, and the achievements are given by the teacher after the completion of each experiment according to the on-site situation; (3)Final hands-on achievements: The students are randomly selected to complete the experimental program randomly selected, and its purpose is to examine the usual experimental effect of the students; (4)Extracurricular preview mainly refers to the participation of the students in case of preview with MLR, which is mainly to examine whether the students preview and think independently. These four parts account for a certain proportion. Such examination method not only can make the students attach importance to the usual experimental process, and mobilize the student's enthusiasm and initiative, but also can really improve the student's experimental operation, analysis and ability to solving problems.

\section{CONCLUSIONS}

The application of MLR in teaching of experimental links of embedded system is conductive to effective connection of before class, in class and after class. The students realize autonomous learning, repeated learning and real-time learning with MLR, to improve the student's learning initiative and enhance the student's self-confidence, which can effectively make up the deficiency in the existing teaching process. At the same time, design and production of MLR not only deepen the teacher's understanding of teaching content, and broaden the horizons, but also improve the teacher's modern information technology level. The author believes that the application of MLR in information course teaching of colleges and universities at all levels as well as talent training institutions is feasible.

\section{REFERENCES}

[1] Eileen Hulme, Ben Thomas, Hal Delarosby, "Developing Creativity Ecosystems: Preparing College Students for Tomorrow's Innovation Challenge,"About Campus 2014,19(1): 14-23.

[2] John F. Montgomery, Jill Arensdorf "Preparing Globally Competent Leaders through Innovative Study Abroad Experiences" Journal of Leadership Studies 2012,6 (1) : $64-71$.

[3] LI Zu-chao WANG Jia-xun. Experience and Characteristics of Innovative Sci-tech Talent Cultivation in American research-oriented Universities. TSINGHUA JOURNAL OF EDUCATION, 2016, 37(2):35-43.

[4] Guo Shaoqing, Yang Bin. Research on the Promotion of Flipped Classroom Teaching Strategies by Using Convergent Evolution Micro Courses Instructional Design in University. China Academic Journal Electronic. 2014, 327:98-103.

[5] Zou Yan, Wang Jihun, Wang Hongmei. Large Level Practices Cooperative Education Platform Based on Interdisciplinary. RESEARCH AND EXPLORATION IN LABORATORY. 2015,34(1): 219-221. 